\title{
Optimization of Surface Roughness in Turning Operation of EN8 using Taguchi Method
}

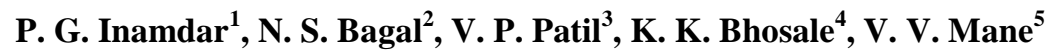 \\ Student, Mechanical Department, Satara College of Engineering \& Management Limb, Satara, India ${ }^{1}$ \\ Assistant Professor, Mechanical Department, Dr. Daulatrao Aher College of Engineering, Karad, India 2, 3,4 \\ Research Assistant, M.S. Industrial Engineering, Iowa State University, Ames Iowa, USA ${ }^{5}$
}

\begin{abstract}
The main aim of this paper is to optimise the surface roughness in conventional turning operation using Taguchi Method for the material medium carbon steel EN8. In this work cutting speed, feed rate and depth of cut are taken as performance parameters to achieve better surface roughness. Taguchi Method is used to obtained the main parametric effect on the surface roughness using there levels and factors. L9 orthogonal array is used to design the experiments. Also analysis of variance (ANOVA) was carried out with the significance factor of 95\%. After the experimentation, it was found that cutting speed has more influenced on the surface roughness in conventional turning process than feed rate and depth of cut.
\end{abstract}

Keywords: Taguchi method, Optimisation, Surface roughness, EN8.

\section{INTRODUCTION}

In today's manufacturing industrial scenario there is induction hardening processes. From the automotive trade requirement of machining process with the high quality at to wider general engineering applications, EN8 is popular low cost and wastage. To achieve this requirement there is steel in industry.

need of optimisation of performance parameters. In the machining process, apart from obtaining the accurate dimensions, achieving a good surface quality and required metal removal rate are importance characteristics. A machining process involves many process parameters which directly or indirectly influence the surface roughness and metal removal rate of the metal. There are several machining processes like turning, grinding, boring, drilling, milling etc. Mostly in the manufacturing industry turning process is mostly used. Surface roughness and metal removal in turning process are depending on various parameters as feed rate, spindle speed, depth of cut.

Taguchi Method is one of several methods to achieved optimise process parameters of machining. Taguchi Technique is statistical method to improve performance parameters and widely applicable for engineering, biotechnology, advertisement and marketing. Taguchi transformed the manufacturing process in Japan through cost savings. Taguchi methods identified noise sources, which have the greatest effects on product variability. Taguchi method adopted by successful manufacturers around the globe because of their optimised results in creating superior production processes at much lower costs. The main objective of Taguchi method is to design robust processes with different operating conditions.

EN8 is medium carbon steel which is used in applications where better properties than mild steel are required but where the costs do not justify the purchase of a steel alloy. EN8 can be heat treated to provide a good surface hardness and moderate wear resistance by flame or

\section{PROBLEM STATEMENT \& OBJECTIVE}

Conventional machining offers different types of operations. In turning operation it is difficult to achieve desired surface roughness with undefined performance parameters.

The objective of this work is as follows,

1. To achieve the desired surface roughness by optimizing performance parameters for turning operations.

2. To study effect of parameters on the surface roughness value $(\mathrm{Ra})$.

The scope of the study was limited up to conventional turning process. The material used for study purpose untreated medium carbon steel EN8. The study focuses on to the optimize performance parameter for conventional turning operation with material EN8.

\section{III.METHODOLOGY}

The present work deals with the turning of hard material as EN8 on lathe machine. It is an important engineering material employed in manufacturing of components in automotive industries. The experiment deals with machining of medium carbon steel EN8 was carried out with High Speed Steel tool in conventional lathe. . The chemical composition of EN8 described in table no. I. 
IARJSET

International Advanced Research Journal in Science, Engineering and Technology

National Conference on Design, Manufacturing, Energy \& Thermal Engineering (NCDMETE-2017) AGTI's Dr. Daulatrao Aher College Engineering, Vidyanagar Extension, Karad

Vol. 4, Special Issue 1, January 2017

TABLE I CHEMICAL COMPOSITION OF EN8

\begin{tabular}{|c|c|c|c|c|}
\hline $\mathrm{C}$ & $\mathrm{Si}$ & $\mathrm{Mn}$ & $\mathrm{P}$ & $\mathrm{S}$ \\
\hline 0.38 & 0.15 & 0.85 & 0.03 & 0.03 \\
\hline
\end{tabular}

Solid round bar of EN8 steel with $35 \mathrm{~mm}$ diameter and $100 \mathrm{~mm}$ long were used as the work piece. In conventional turning operation surface roughness value is affected by the several parameter such as cutting speed, depth of cut, feed rate, spindle speed, work piece material, tool material, working operating conditions.

Performance parameters as cutting speed, depth of cut and feed rate are the influenced factors on surface roughness value and others are nuisance factors. Turning experiments were carried out at three different cutting speeds (v) which were 200, 300 and $400 \mathrm{rpm}$ and feed rates (f) were $0.2,0.4,0.8 \mathrm{~mm} / \mathrm{rev}$ and depth of cut (d) were $0.2,0.4$ and $0.6 \mathrm{~mm}$ for the experimentation and small depth of cut was used for finish turning. The factors and their levels considered in this study are shown in Table II.

\section{TABLE III FACTORS AND LEVELS USED IN EXPERIMENT}

\begin{tabular}{|c|c|c|c|}
\hline \multirow{2}{*}{ Factors } & \multicolumn{3}{|c|}{ Levels } \\
\cline { 2 - 4 } & 1 & 2 & 3 \\
\hline Cutting Speed (rpm) & 200 & 300 & 400 \\
\hline Feed Rate (mm/rev) & 0.2 & 0.4 & 0.8 \\
\hline Depth of Cut (mm) & 0.2 & 0.4 & 0.6 \\
\hline
\end{tabular}

The selection of design parameter factors is the important in the design of experiments. Taguchi method is to optimize the process parameter to achieve best quality performance. It is one of the powerful statistical tools used in the application of design and analysis for experiments adopted to optimize the design parameter and it is an effective approach to produce high-quality products at a relatively low cost. Taguchi analysis is carried out using Minitab 17 statistical software. If the number of process parameter increases, there are number of experiments have to be conducted to get the optimized parameter. To make the task easy, Taguchi method uses design of orthogonal arrays (OA) to study the process parameter with small number of experiments. The present experimental investigation deals with the design of experiment by the Taguchi methodology with a L9 orthogonal array (OA) to determine the importance of the factors or the parameters. Nine experiments with combination of different cutting parameters are randomly conducted.

TABLE IIIII L ${ }_{9}$ ORTHOGONAL ARRAY

\begin{tabular}{|c|c|c|c|}
\hline $\begin{array}{c}\text { Sr. } \\
\text { No. }\end{array}$ & $\begin{array}{c}\text { Cutting } \\
\text { Speed (rpm) }\end{array}$ & $\begin{array}{c}\text { Feed Rate } \\
(\mathrm{mm} / \mathrm{rev})\end{array}$ & $\begin{array}{c}\text { Depth of Cut } \\
(\mathrm{mm})\end{array}$ \\
\hline 1 & 1 & 1 & 1 \\
\hline 2 & 1 & 2 & 2 \\
\hline 3 & 1 & 3 & 3 \\
\hline 4 & 2 & 2 & 2 \\
\hline
\end{tabular}

\begin{tabular}{|l|l|l|l|}
\hline 5 & 2 & 3 & 3 \\
\hline 6 & 2 & 1 & 1 \\
\hline 7 & 3 & 3 & 3 \\
\hline 8 & 3 & 1 & 1 \\
\hline 9 & 3 & 2 & 2 \\
\hline
\end{tabular}

The surface roughness ( $\mathrm{Ra}$ ) of the work piece is measured by using Surface Roughness Tester as shown in figure no. 1 at Production Engineering Department in College of Engineering Pune. The instrument was calibrated using a standard calibration block prior to the measurements. The measurement was taken at four locations (90 apart) around the circumference of the work piece.

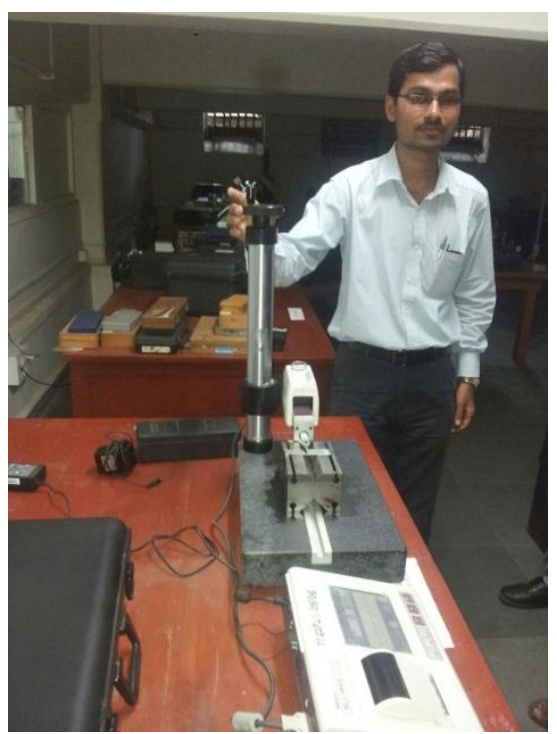

Figure No. 1 Photography of Measurement of Ra value

\section{RESULT AND DISCUSSION}

The Taguchi method uses a special design of orthogonal array (OA) in order to study the entire parameter space with a small number of experiments. The full factorial design could require $3 \times 3=27$ experimental runs, which would make the effort and experimental cost prohibitive and unrealistic. However, the experimental design of an OA can be of nine experiments.

\section{TABLE IVV L ${ }_{9}$ ORTHOGONAL ARRAY (RESUlT OF TAGUCHI ANALYSIS)}

\begin{tabular}{|c|c|c|c|}
\hline $\begin{array}{c}\text { Cutting } \\
\text { Speed }(\mathrm{rpm})\end{array}$ & $\begin{array}{c}\text { Feed Rate } \\
(\mathrm{mm} / \mathrm{rev})\end{array}$ & $\begin{array}{c}\text { Depth of } \\
\text { Cut }(\mathrm{mm})\end{array}$ & $\begin{array}{c}\text { Ra } \\
(\mu \mathrm{m})\end{array}$ \\
\hline 200 & 0.2 & 0.2 & 3.97 \\
\hline 200 & 0.4 & 0.4 & 4.21 \\
\hline 200 & 0.8 & 0.6 & 4.3 \\
\hline 300 & 0.2 & 0.4 & 4.25 \\
\hline 300 & 0.4 & 0.6 & 4.28 \\
\hline 300 & 0.8 & 0.2 & 4.25 \\
\hline 400 & 0.2 & 0.6 & 4.3 \\
\hline 400 & 0.4 & 0.4 & 4.27 \\
\hline 400 & 0.8 & 0.2 & 4.42 \\
\hline
\end{tabular}


IARJSET

International Advanced Research Journal in Science, Engineering and Technology

National Conference on Design, Manufacturing, Energy \& Thermal Engineering (NCDMETE-2017)

AGTI's Dr. Daulatrao Aher College Engineering, Vidyanagar Extension, Karad

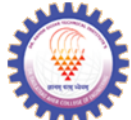

Vol. 4, Special Issue 1, January 2017

Only main effects were considered, whereas interaction smaller-the-better criterion for surface roughness is shown effects were assumed to be negligible. In Taguchi method, in Table V. An influence of each design parameter (speed, the experimental results were transformed into $\mathrm{S} / \mathrm{N}$ ratios feed and depth of cut) on surface roughness is obtained to measure the quality characteristics deviating from the from the response tables of $\mathrm{S} / \mathrm{N}$ ratio. Taguchi desired value. The $\mathrm{S} / \mathrm{N}$ ratio is the ratio of the mean recommends that the larger $\mathrm{S} / \mathrm{N}$ ratio corresponds to the (signal) to the standard deviation (noise). Regardless of the best quality characteristics, regardless of the category of category of the quality characteristic, a greater $\mathrm{S} / \mathrm{N}$ ratio the performance characteristic. Therefore, the optimal corresponded to better quality characteristics. The method level of process parameter is the level with the highest $\mathrm{S} / \mathrm{N}$ of calculating the $\mathrm{S} / \mathrm{N}$ ratio depends at each run of the ratio. So feed rate is having the highest $\mathrm{S} / \mathrm{N}$ ratio. The experiment on whether the quality characteristic is lower- response table for mean is shown in Table VI. the-better, higher-the-better, or nominal-the-better.

TABLE V RESPONSE TABLE For SIGNAL TO NOISE RATIO

\begin{tabular}{|c|c|c|c|}
\hline Level & $\begin{array}{c}\text { Cutting } \\
\text { Speed }\end{array}$ & Feed Rate & $\begin{array}{c}\text { Depth of } \\
\text { Cut }\end{array}$ \\
\hline 1 & -12.38 & -12.40 & -12.38 \\
\hline 2 & -12.59 & -12.57 & -12.65 \\
\hline 3 & -12.73 & -12.72 & -12.66 \\
\hline Delta & 0.35 & 0.31 & 0.27 \\
\hline Rank & 1 & 2 & 3 \\
\hline
\end{tabular}

In the present study, $\mathrm{S} / \mathrm{N}$ ratio is calculated as the logarithmic transformation of the loss function by using smaller-the-better criterion as minimum values of surface roughness is required. $\mathrm{S} / \mathrm{N}$ ratio is calculated based on
TABLE VI RESPONSE TABLE For Signal To NOISE RATIO MEANS

\begin{tabular}{|l|l|l|l|}
\hline Level & $\begin{array}{l}\text { Cutting } \\
\text { Speed }\end{array}$ & Feed Rate & $\begin{array}{l}\text { Depth of } \\
\text { Cut }\end{array}$ \\
\hline 1 & 4.160 & 4.173 & 4.163 \\
\hline 2 & 4.260 & 4.253 & 4.293 \\
\hline 3 & 4.330 & 4.323 & 4.293 \\
\hline Delta & 0.170 & 0.150 & 0.130 \\
\hline Rank & 1 & 2 & 3 \\
\hline
\end{tabular}

Results of analysis of variance indicate that feed rate is the most significant machining parameter followed by cutting speed affecting the surface roughness.

TABLE VII ANALYSIS OF VARIANCE FOR SIGNAL TO NOISE RATIO

\begin{tabular}{|l|c|c|c|c|c|c|}
\hline Level & DF & Seq. SS & Adj. SS & Adj. MS & F & P \\
\hline $\begin{array}{l}\text { Cutting } \\
\text { Speed }\end{array}$ & 2 & 0.18819 & 0.18819 & 0.09409 & 9.98 & 0.09 \\
\hline $\begin{array}{l}\text { Feed } \\
\text { Rate }\end{array}$ & 2 & 0.14539 & 0.14539 & 0.07269 & 7.71 & 0.11 \\
\hline $\begin{array}{l}\text { Depth of } \\
\text { cut }\end{array}$ & 2 & 0.14674 & 0.14674 & 0.07337 & 7.78 & 0.14 \\
\hline $\begin{array}{l}\text { Residual } \\
\text { Error }\end{array}$ & 2 & 0.01885 & 0.01885 & 0.00942 & & \\
\hline Total & 8 & 0.49917 & & & & \\
\hline
\end{tabular}

The main effect plots for means and for $\mathrm{S} / \mathrm{N}$ ratios of surface roughness are presented in fig. 1 (a) and fig. 1 (b) respectively.

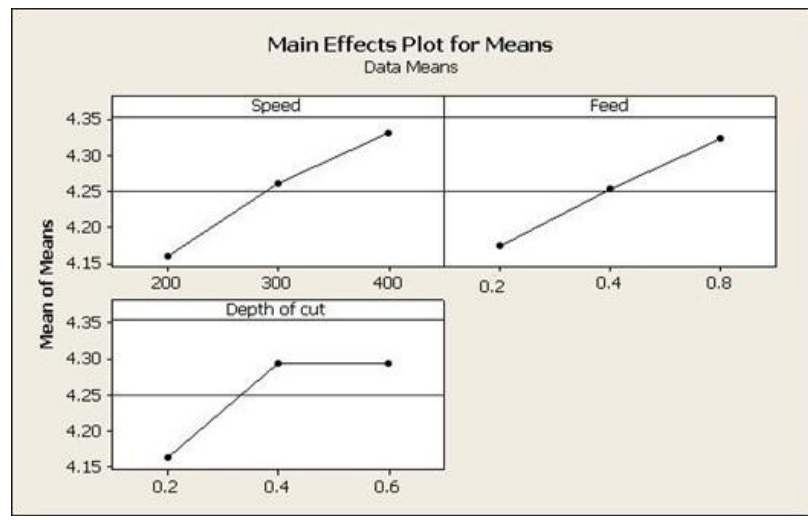

Figure No. 1 (a) Main Effect Plot for means

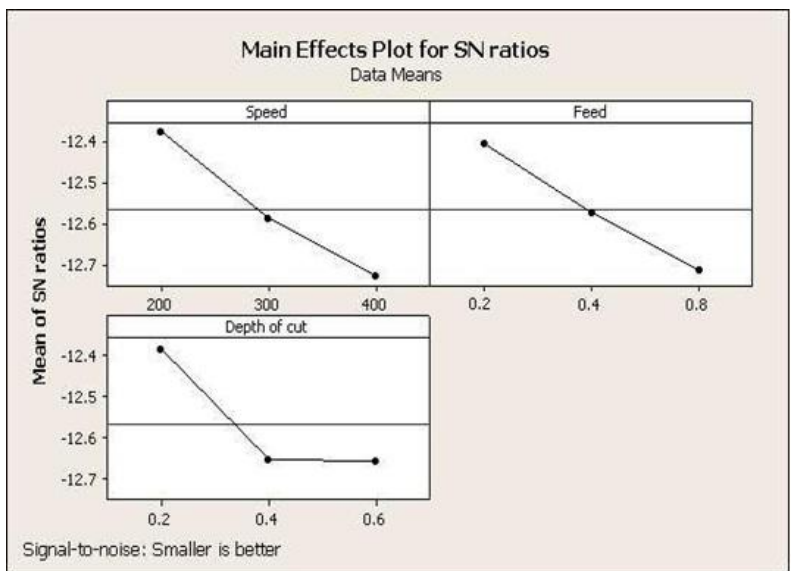

Figure No. 1 (b) Main Effect Plot for SN ratios

In the main effects plots, if the point is near the average horizontal line has less significant effect and the one 


\section{IAR JSET}

which has highest inclination will have most significant effect on the responses. Therefore depth of cut is having the most significant effect on surface roughness

\section{CONCLUSION}

- It has been found that cutting speed is found to be the most significant factor \& its contribution to surface roughness is greater than feed rate and depth of cut.

- The Surface roughness is mainly affected by feed rate, depth of cut and cutting speed. With the increase in feed rate the surface roughness also increases, as the depth of cut increases the surface roughness first increase and decrease and as the cutting speed increase surface roughness decreases.

- From ANOVA analysis, parameters making significant effect on surface roughness are cutting speed and feed rate.

\section{ACKNOWLEDGMENT}

The Authors want to owe their deepest sense of gratitude to Mrs. R. P. Kulkarni, Head of Department, Mechanical Engineering, Satara College of Engineering \& Management Limb, Satara for providing facilities required for the completion of work. Again the moral support from Dr. B. Rajiv, Department of Production, College of Engineering Pune is also appreciated. We are very thankful to all our professors and colleague. Last but not least, our sincere gratitude to our family, because without their patience full support this was not possible.

\section{REFERENCES}

[1]. Mohd. Rafeeq, Mudasir and M Kirmani (2014), “Optimizing Feed and Radial Forces on Conventional Lathe Machine of EN31b Alloy Steel through Taguchi's Parameter Design Approach", Int. Journal of Engineering Research and Applications, Vol. 4, Issue 4, pp.134-14

[2]. S. R. Das, R. P. Nayak and D. Dhupl (2012), "Optimization of Cutting Parameters on Tool Water and Work piece Surface Temperature in Turning of AISI D2 Steel", Internatial Journal of Lean Thinking, Vol. 3, Issue 2, pp. 141-156

[3]. A. Arunkumar and T. Prabaharan (2014), "Optimization of Cutting Parameters in Machining of Polyphenylene Sulphide Composites", International Journal of Innovative Research in Science, Engineering and Technology, Volume 3, Special Issue 3, pp. 1082-1086

[4]. P. Madhava Reddy, P. Vijaya Bhaskara Reddy, Y. Ashok Kumar Reddy and N. Naresh (2014), "Optimization of Machining Parameter for Turning of En 16 Steel Using Grey Based Taguchi Method", ARPN Journal of Engineering and Applied Sciences, Vol. 9, No. 3, pp. 215-222

[5]. Pankaj Sharma and Kamaljeet Bhambri(2012), "Multi-Response Optimization By Experimental Investigation of Machining Parameters in CNC Turning by Taguchi Based Grey Relational Analysis", International Journal of Engineering Research and Applications (IJERA), Vol. 2, Issue 5, pp.1594-1602

[6]. Mihir T. Patel and Vivek A. Deshpande (2014), "Optimization of Machining Parameters for Turning Different Alloy Steel Using CNC -Review", International Journal of Innovative Research in Science Engineering and Technology, Vol. 3, Issue 2, pp. 9423-9430

[7]. Anand S. Shivade, Shivraj Bhagat, Suraj Jagdale, Amit Nikam and Pramod londhe (2014), "Optimization of Machining Parameters for Turning using Taguchi Approach", International Journal of Recent Technology and Engineering, Volume-3, Issue-1, pp. 145-149
8]. Sahoo P (2011), "Optimization of Turning Parameters for Surface Roughness Using RSM and GA", Advances in Production Engineering \& Management, Vol.6, Issue 3, pp 197-208

[9]. L. B Abhang and M Hameedullah (2014), "Parametric Optimization of Machining Parameters using Graph Theory and Matrix Approach", 5th International \& 26th All India Manufacturing Technology, Design and Research Conference, pp. 659.1-659.6

[10]. Ajit Kumar Senapati, Abhijit Bhatta, Avinash Senapati and Omkarnath Mishra, Satyajeet Mohanty, "Effect of Machining Parameters on Cutting Forces during Turning of Mild Steel on High Speed Lathe by using Taguchi Orthogonal Array", Global journal of advanced research, Vol-1, Issue-1, pp. 28-35. 